\title{
Learning from the past to predict the future: an historical analysis of grass invasions in northern Australia
}

\author{
Rieks D. van Klinken • F. Dane Panetta • \\ Shaun Coutts $\cdot$ Bryan K. Simon
}

Received: 8 December 2013/Accepted: 1 July 2014/Published online: 23 July 2014

(C) The Author(s) 2014. This article is published with open access at Springerlink.com

\begin{abstract}
An important focus of biosecurity is anticipating future risks, but time lags between introduction, naturalisation, and (ultimately) impact mean that future risks can be strongly influenced by history. We conduct a comprehensive historical analysis of tropical grasses $(n=155)$ that have naturalised in Australia since European settlement (1788) to determine what factors shaped historical patterns of naturalisation and future risks, including for the 21 species that cause serious negative impacts. Most
\end{abstract}

Electronic supplementary material The online version of this article (doi:10.1007/s10530-014-0749-3) contains supplementary material, which is available to authorized users.

R. D. van Klinken (ه)

CSIRO Biosecurity Flagship and CSIRO Ecosystem

Sciences, EcoSciences Precinct, PO Box 2583, Brisbane,

QLD 4001, Australia

e-mail: Rieks.vanklinken@csiro.au

F. D. Panetta

Melbourne School of Land and Environment, The

University of Melbourne, Parkville, VIC 3010, Australia

S. Coutts

ARC Centre of Excellence for Environmental Decisions, School of Biological Sciences, University of Queensland, Brisbane, QLD 4072, Australia

\section{B. K. Simon}

Queensland Herbarium, Queensland Department of Science, IT, Innovation and the Arts, Brisbane Botanic Gardens Mt Coot-tha, Toowong, QLD 4066, Australia naturalised species were from the Old World (78 \%), were introduced for use in pasture $(64.5 \%)$, were first recorded prior to $1940(84.5 \%)$ and naturalised before 1980 (90.3\%). Patterns for high-impact species were similar, with all being first recorded in Australia by 1940, and only seven naturalised since then-five intentionally introduced as pasture species. Counter to expectations, we found no evidence for increased naturalisation with increasing trade, including for species introduced unintentionally for which the link was expected to be strongest. New pathways have not emerged since the 1930s despite substantial shifts in trading patterns. Furthermore, introduction and naturalisation rates are now at or approaching historically low levels. Three reasons were identified: (1) the often long lag phase between introduction and reported naturalisation means naturalisation rates reflect historical trends in introduction rates; (2) important introduction pathways are not directly related to trade volume and globalisation; and (3) that species pools may become depleted. The last of these appears to be the case for the most important pathway for tropical grasses, i.e. the intentional introduction of useful pasture species. Assuming that new pathways don't arise that might result in increased naturalisation rates, and that current at-border biosecurity practices remain in place, we conclude that most future high-impact tropical grass species are already present in Australia. Our results highlight the need to continually test underlying assumptions regarding future naturalisation rates of high-impact invasive species, as 
conclusions have important implications for how best to manage future biosecurity risks.

Keywords Globalisation - Invasive plants · Introduction pathways - Lag phases - Pasture grass · Poaceae $\cdot$ Sleeper weeds $\cdot$ Transformers $\cdot$

Weed risk assessment

\section{Introduction}

A critical aspect of biosecurity is anticipating and responding to the risks posed by invasive alien species (IAS). The often long lag phases reported between introduction, invasion and impact (Kowarik 1995; Ewel et al. 1999; Caley et al. 2008; Aikio et al. 2010) mean that current invasions are widely viewed as reflecting the legacy of historical activities (invasion debt) (Essl et al. 2011). However, drivers of new introductions, invasion and impact continue to change, thereby altering risk profiles well into the future. The modern increase in international trade through the "era of globalisation" (Hulme 2009) is generally considered as one of the most important changes and its role in increasing the risks from IAS has become axiomatic (Ewel et al. 1999; Lowe 2004; Meyerson and Mooney 2007; Westphal et al. 2008; Hulme 2009; Perrings et al. 2010). When combined with lag-effects it suggests that we are entering the "homogocene" following the breakdown of biogeographical barriers (Rosenzweig 2001). This has led to calls for increasing biosecurity resources directed at the border (Westphal et al. 2008). However, surprisingly few studies test these hypotheses beyond correlating patterns of naturalisation and trade, and few test the role of history in shaping invasion risks more generally (Westphal et al. 2008). Furthermore, few studies examine whether any general patterns also apply to invaders that cause serious harm (Caley et al. 2008; van Klinken et al. 2013), which are the primary focus of biosecurity. The expectation that the risk of invasion by new organisms is increasing through time as a result of globalisation and increased trade is supported by increasing trends in naturalisation rates of diverse taxa (Hulme 2009), including plants (Groves 1998; Pyšek et al. 2009). For example, a doubling in the number of naturalisations between 1970 and 1995 has been observed in Australia (Groves 1998). Furthermore, an analysis of IAS showed that increasing international trade was the best predictor for IAS richness (Westphal et al. 2008). However, trends in naturalisation rates do not necessarily reflect trends in introduction rates, as lag phases between the two can be considerable (Kowarik 1995; Caley et al. 2008; Daehler 2009). The underlying links between globalisation, patterns of introductions and resulting changes in naturalisation rates therefore remain largely untested.

Certainly the importance of different pathways has varied historically (Mack and Erneberg 2002; Cook and Dias 2006). For example, invasion sources and pathways for exotic grasses into Australia have changed with trading patterns and with changing motivation for introducing exotic species (Mack and Erneberg 2002; Cook and Dias 2006). This resulted in at least $22 \%$ (2,250 species, as 33,499 accessions) of the world's grass species being intentionally imported into Australia since initiation of records in 1929 through to the late 1980s (Cook and Dias 2006; van Klinken et al. 2013). The rate of new introductions of woody perennials in nursery catalogues into South Australia has also decreased through the 1900s (Caley et al. 2008). In addition, there have been significant changes in biosecurity policy in several countries in recent decades (Pheloung 2001), and one might expect a resulting decrease in rate of importations of new species and subsequently of naturalisations.

Biosecurity policy is ultimately aimed at reducing the threat of species that could cause serious impact, rather than reducing the rates of importation or naturalisation per se. A key question, therefore, is whether the historical drivers for high-impact species are the same as for species in general. If this is the case, we would expect any changes in historical drivers of importation, naturalisation, and invasion to elicit a proportional response in high-impact species. Comparative studies between naturalised species and the subset that have caused serious impact have identified predictors of impact that apply to at least some taxa or impacted sectors. For example, an analysis of naturalised subtropical and tropical grasses in Australia showed that high-impact species were more likely to be semi-aquatic and have faster spread rates when measured as regions invaded per decade naturalised, although the latter may not be explanatory (van Klinken et al. 2013). However, few studies test whether species that result in serious impacts have invasion histories that differ from those that don't. One 
exception was an analysis of lag phases between first records in nursery catalogues and recorded naturalisations, which showed that lag phases for "major" weeds were shorter than for "insignificant weeds" (Caley et al. 2008).

We conduct an analysis to test the roles of historical changes in trading partners and invasion pathways in shaping patterns of importation and naturalisation, including testing whether species that go on to cause serious impacts are unique in any way. The necessary data on importation, naturalisation and impact are generally difficult to source across taxa or regions. We therefore focus on the 155 subtropical and tropical grass species that naturalised in Australia since European settlement in 1788, and the subset of 21 species that currently cause serious impacts to the environment and production. This data set was used previously to test for predictors of high-impact species (van Klinken et al. 2013). Grasses are typically one of the bestrepresented naturalised families (Groves 1998; Pysek et al. 2012) and their resulting negative impacts to the environment and industry can be particularly severe (Mack 1989; D'Antonio and Vitousek 1992; Ferdinands et al. 2005; Groves et al. 2005; Setterfield et al. 2010; Friedel et al. 2011; van Klinken et al. 2013).

Introduction of grass species for use in pasture was of particular importance in Australia, resulting in the largest tropical forages (grasses and legumes) collection in the world by 1984 (Eyles and Cameron 1985), and many naturalisations (Lonsdale 1994; Cook and Dias 2006; van Klinken et al. 2013). The history of the pasture research programme has been described in detail by Eyles and Cameron (1985) and others (Holtze 1890; Winter et al. 1985; Mott 1986; Lonsdale 1994; Chudleigh and Bramwell 1996; Cook and Dias 2006). Government botanists and acclimatisation societies developed a strong interest in tropical pasture grasses in the late nineteenth century, followed by the commencement of more intensive testing by government agencies from the 1920s through to the start of WW2. Commencement of the Commonwealth Plant Introduction (CPI) list in 1929 marks the start of systematic, recorded plant introductions into Australia. Activities increased after WW2, with a much more coordinated programme that aimed to underpin agricultural development by transforming the native vegetation to exotic pastures, and continued through to the 1990s.

We describe the invasion history of sub-tropical and tropical grasses in Australia, test historical and biological predictors for invasion history, and assess whether species that ultimately cause high impacts are different in any way (from the general pool of naturalisations). This includes testing whether introduction rates have continued to increase, as might be expected with increasing globalisation. The CPI list allowed us to assess the role systematic pasture research played in shaping the history of grass invasions in Australia. We also compared patterns for grass naturalisation with those for all plant species naturalised in Australia between 1971 and 1995 (Groves 1998) to gauge the generality of our findings. The biosecurity implications of our findings are discussed.

\section{Methods}

A comprehensive list of 155 tropical and subtropical grass species that had established naturally selfsustaining populations (Richardson et al. 2000) in Australia prior to 2010 was taken from van Klinken et al. (2013). Of these, 21 species were assessed as high-impact, based on evidence against set criteria developed for each affected sector (van Klinken et al. 2013). For the environment sector this procedure identified species that have become dominant in environmentally important habitats as a result of natural spread, and not dependent on human related disturbance. For plant industry (pastoral, cropping and horticulture), high-impact species were those that the respective sector considered as currently having a serious negative impact, therefore requiring specifically targeted control work or significantly altered onfarm practice. The latter excluded species whose impacts are largely preventable through industrystandard practice, and 'systems weeds' such as many cropping weeds, that are managed as part of a suite of competitors.

We recorded whether each species was highimpact, its native region of origin, date of first record and first record of naturalisation in Australia, whether the species was recorded on the Commonwealth Plant Introduction (CPI) records and, if so, when it was first recorded (Cook and Dias 2006). The most likely pathway of entry into Australia was identified using a wide range of published and unpublished sources, including herbarium records, the literature and CPI records. We did not consider species recorded only 
Table 1 Predictor and response variables used to predict the year of first record for each grass species

\begin{tabular}{|c|c|c|c|}
\hline Variable & Type & Units or levels & Explanation \\
\hline \multicolumn{4}{|l|}{ Historical } \\
\hline first.rec & Continuous & Year & Year the species was first recorded in Australia \\
\hline Intro & Categorical & 5 pathways & The introduction pathway into Australia \\
\hline spr.rate & Continuous & regions/decade & $\begin{array}{l}\text { Number of regions in which the species is recorded as naturalised divided by the } \\
\text { number of decades since the species first became naturalised }\end{array}$ \\
\hline act.spr & Binary & (no, yes) & Was the species actively spread and promoted by people? \\
\hline \multicolumn{4}{|l|}{ Biological } \\
\hline high.imp & Binary & (no, yes) & $\begin{array}{l}\text { Does the species meet one of the criteria for high impact in van Klinken et al. } \\
\text { (2013)? }\end{array}$ \\
\hline Native origin & Categorical & 9 regions & Native to which of six global biogeographic regions (or combinations thereof) \\
\hline semi.aqua & Categorical & (no, yes) & Is the species semi-aquatic? \\
\hline
\end{tabular}

from experimental plots or as ornamentals. The most likely introduction pathway was categorised as: pasture or turf, contaminant of imported seeds, crop, ornamental, or unexplained. For some species there were multiple introduction and naturalisation events, and potentially more than one pathway for introduction, in which case the primary pathway was identified based on what the species was eventually used for in Australia. Native origin was classified as Eurasian, Australasian, Oriental (including Pakistan, India, south-east Asia and China), Afro-tropical, Nearctic and Neotropical, or combinations thereof.

All models and statistical tests were carried out in the statistical computing language R (R Core Team 2012).

\section{Origins and pathways}

We used a randomisation to test whether species from different regions were more or less likely than chance to be introduced by different pathways. The randomisation was constrained so that the number of species from each region and the number that arrived by each pathway was preserved. The constrained matrix shuffle (100,000 randomisations) was carried out using the vegan package (Oksanen et al. 2013). To build a null distribution we recorded the number of species in each region/pathway combination for each randomly shuffled matrix. This distribution gave the expected number of species in each region/pathway combination if the number of species introduced from each region was not affected by pathway. The $p$ value for each region/pathway combination was the proportion of species counts in the null distribution as, or more, extreme than the relevant observed species count. A separate randomisation was carried out to test whether high-impact species from different regions were more or less likely than chance to be introduced by different pathways.

\section{History of importation}

We used mixed effects models with a normal error distribution to predict the year of first record for each species. The predictors (Table 1), included whether or not a species is high-impact, spread rate (in regions per decade), if the species was actively spread and if it was semi-aquatic. Genus was also tested as a random effect but explained virtually none of the variation in the data and so was dropped from the analysis. The effects of two predictors, origin and introduction pathway, were treated as random. To make the model coefficients of categorical variables easier to interpret we centred the year of first record so that its mean was 0 .

Our data set contained only 155 species, which restricted the number of parameters we could fit. To check that we did not miss any important two-way interactions, we fitted models with each two-way interaction one at a time and used AIC to compare model performance. This was done using the lme4 library (Bates and Bolker 2012). It highlighted four interactions as important: act.spr:semi.aqua, spr.rate:high.imp, act.spr:high.imp and high.imp:semi.aqua. We explored the model with all main effects and these four two-way interactions in more detail, using Markov Chain Monte Carlo (MCMC) sampling in R2jags (Su and Yajima 2012) to generate credible intervals for each parameter. Of the two-way 
interactions highlighted in the previous step, act.spr:semi.aqua, act.spr:high.imp and high.imp:semi.aqua had wide credible intervals that easily encompassed zero, and so were dropped from the analysis. For simplicity we use only the main fixed and random effects, and the two-way interaction spr.rate:high.imp, to predict year of introduction (model 1).

$$
\begin{aligned}
\text { first.rec }= & \text { spr.rate }+ \text { act.spr }+ \text { high.imp } \\
& + \text { semi.aqua }+ \text { high.imp }: \text { semi.aqua }+ \text { intro }_{\mathrm{i}}+\text { origin }_{\mathrm{j}}
\end{aligned}
$$

where intro ${ }_{i}$ is the difference from the global intercept for the ith introduction pathway (i.e. the effect size) and is drawn from a normal distribution with a mean of $\mathrm{mu}_{\mathrm{i}}$ and a globally estimated standard deviation, $\sigma_{\text {intro }}$

intro $_{\mathrm{i}} \sim \mathrm{N}\left(\mathrm{mu}_{\mathrm{i}}, \sigma_{\text {intro }}\right)$

origin $_{\mathrm{i}}$ is the difference from the global intercept for the jth species origin and is drawn from a normal distribution with a mean of $\mathrm{mu}_{\mathrm{j}}$ and a globally estimated standard deviation, $\sigma_{\text {origin }}$

$\operatorname{origin}_{\mathrm{j}} \sim \mathrm{N}\left(\mathrm{mu}_{\mathrm{j}}, \sigma_{\text {origin }}\right)$

Checks for convergence and effective sample size on the MCMC chains were carried out using the coda library (Plummer et al. 2006). For models predicting first record we generated 100,000 MCMC samples. We discarded the first 50,000 to ensure the chain had converged and we took every fifth sample in the chain to reduce auto-correlation.

Testing cause of observed reduction in naturalisation rate

Results showed a decrease in naturalisation rates since the 1930s for species introduced as pasture (see results section). Using a generalised linear model we tested whether the probability of CPI-listed species becoming naturalised decreased with increasing year of introduction. This would support the hypothesis that suitable pasture species were becoming increasingly difficult to source. We included only species listed on the CPI up to and including 1972, the last year a C4 grass that successfully naturalised was first listed on the CPI. This also pre-dates many modern biosecurity measures (see Discussion).

We limited the analysis to species with a $\mathrm{C} 4$ photosynthetic pathway, which is common to most tropical and subtropical grass species. Most naturalized species in our study are C4 (95.5\%, van Klinken et al. 2013) and C4 grass species were readily extracted from CPI records (Cook and Dias 2006). $\mathrm{C} 4$ grass species first recorded on the CPI was taken from data compiled from published records by $\mathrm{G}$. Cook (pers. comm., see also Cook and Dias 2006), and $\mathrm{C} 4$ species that became naturalised following introduction under the CPI scheme from van Klinken et al. (2013). We excluded CPI-listed species that had already naturalised prior to CPI-listing. We only considered species first imported at least 38 years ago, which is longer than the average lag phase (see results). Any decline is therefore unlikely to reflect long lag phases to naturalisation. The response was a two column vector, the first column giving the number of species introduced in a given year that went on to naturalise by 2010 (the last date for which we have data). The second column was the number of species introduced in a given year that failed to naturalise by 2010. The probability of a species becoming naturalised by 2010 was predicted by year of listing on the CPI (centered so the mean was 0). We fitted the model:

$\operatorname{Pr}($ nat $)=$ yearCPI

with a binomial error structure.

Comparison between our study and all naturalised flora

The best published, comparative data we could find for all naturalised flora in Australia were for pathways of introduction for species that naturalised between 1970 and 1995 (Groves 1998). We compared these summary statistics with grasses that were first recorded and first naturalised during this period.

\section{Results}

Origins and introduction pathways of naturalised species

Most of the 155 naturalised species are native to either the Old World (65.8\%), especially the Afrotropical region $(35.5 \%)$, or the Americas (23.9\%) (Table 2). The remaining six species are native to Australasia (two species) or have a native range that is thought to span multiple biogeographic regions (four species). 
Table 2 Observed number of tropical grass species from each biogeographic region introduced into Australia via each pathway for all species (a) and high-impact species (b)

\begin{tabular}{|c|c|c|c|c|c|c|}
\hline \multirow[t]{2}{*}{ Biogeographic region } & \multicolumn{6}{|c|}{ Introduction pathway } \\
\hline & Contaminant & Crop & Ornamental & Pasture/turf & Unexplained & Total \\
\hline \multicolumn{7}{|l|}{ (a) All species } \\
\hline \multicolumn{7}{|l|}{ Old World } \\
\hline Afro-Eurasia & 0 & 0 & 0 & 1 & 0 & 1 \\
\hline Eurasian & 0 & 2 & 0 & 5 & 2 & 9 \\
\hline $\begin{array}{l}\text { Afro-Eurasia \&/or } \\
\text { Oriental }\end{array}$ & 1 & $\mathbf{0}(-)$ & 1 & 19 & 6 & 27 \\
\hline Afrotropical & $8(+)$ & $2(-)$ & 2 & $40(+)$ & $\underline{3(-)}$ & 55 \\
\hline Oriental & 3 & 3 & $\underline{4(+)}$ & $\underline{8(-)}$ & 2 & 20 \\
\hline \multicolumn{7}{|l|}{ New world } \\
\hline Neotropical & 1 & 4 & 0 & 17 & 3 & 25 \\
\hline $\begin{array}{l}\text { Neotropical \& } \\
\text { Nearctic }\end{array}$ & 1 & 0 & 0 & 7 & $4(+)$ & 12 \\
\hline Australasia & 0 & $\underline{2(+)}$ & 0 & 0 & 0 & 2 \\
\hline Widely distributed & 0 & 0 & 0 & 3 & 1 & 4 \\
\hline Total & 14 & 13 & 7 & 100 & 21 & 155 \\
\hline \multicolumn{7}{|l|}{ (b) High-impact species } \\
\hline \multicolumn{7}{|l|}{ Old World } \\
\hline Afro-Eurasia & 0 & 0 & 0 & 0 & 0 & 0 \\
\hline Eurasian & 0 & 0 & 0 & 0 & 1 & 1 \\
\hline \multicolumn{7}{|l|}{ Afro-Eurasia \&/or } \\
\hline Oriental & 0 & 0 & 0 & $5(+)$ & 0 & 5 \\
\hline Afrotropical & $3(+)$ & 0 & 0 & 6 & 0 & 9 \\
\hline Oriental & $\underline{2(+)}$ & 0 & 0 & 0 & 0 & 2 \\
\hline \multicolumn{7}{|l|}{ New world } \\
\hline Neotropical & 1 & 0 & 0 & 2 & 0 & 3 \\
\hline $\begin{array}{l}\text { Neotropical \& } \\
\text { Nearctic }\end{array}$ & 0 & 0 & 0 & 0 & 0 & 0 \\
\hline Australasia & 0 & 0 & 0 & 0 & 0 & 0 \\
\hline Widely distributed & 0 & 0 & 0 & 1 & 0 & 1 \\
\hline Total & 6 & 0 & 0 & 14 & 1 & 21 \\
\hline
\end{tabular}

Observed counts as or more extreme than 90 and $95 \%$ of randomly generated counts are in bold and bold-underlined, respectively. Plus and minus signs by significant $p$ values indicate whether the observed count was greater $(+)$, or less $(-)$ than expected at random

Five of the seven species from the five poorlyrepresented subfamilies (Aristidoideae, Arundineae, Bambusoideae, Ehrhartoideae and Micrairoideae) are Oriental. The 21 high-impact species had a representation similar to that of the total pool of naturalised species (Table 2).

At least $100(64.5 \%)$ species were probably introduced as pasture or turf (Table 2). Species of Oriental origin were significantly less likely to be introduced as pasture and more likely to be introduced for ornamental purposes (Table 2). Both Australasian species were introduced as crops, which was more than expected by chance (Table 2). Unexplained introductions were more likely to be native to the Americas, and less likely to be from the Afro-tropics (Table 2). Species from the Afro-tropical region were also more likely than chance to arrive as a contaminant and as pasture or turf, and less likely than chance to arrive as a crop (Table 2). Widespread Old World species were less likely than chance to arrive as a crop (Table 2). 
(a) First records of all species ( $n=155)$

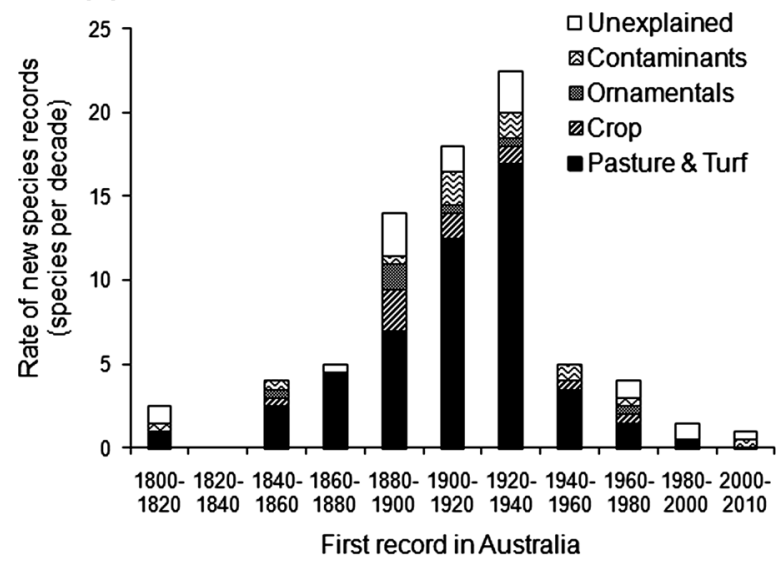

(c) Naturalisation of all species ( $n=155)$

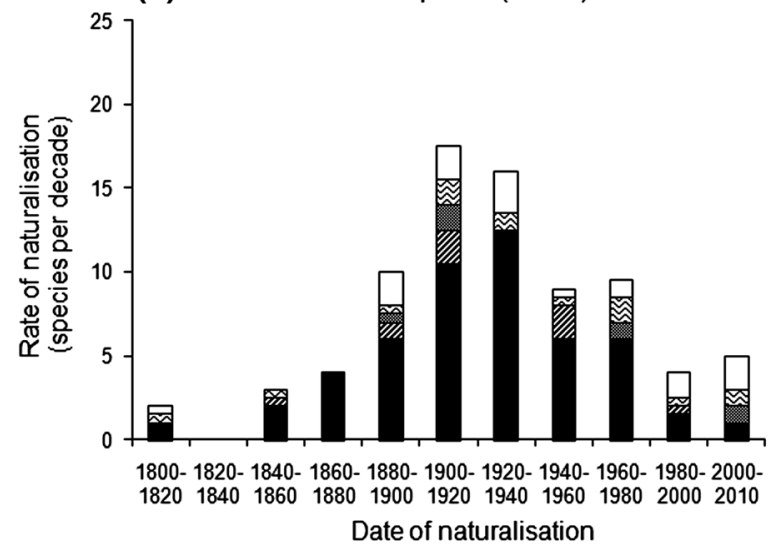

Fig. 1 Rate of first records and naturalisations of naturalised and high-impact tropical, Australian, grass species, grouped by pathway. Rate of new records $(\mathbf{a}, \mathbf{b})$ and naturalisations $(\mathbf{c}, \mathbf{d})$ are

There were differences in origin and pathway between all naturalised species and high-impact species, although sample sizes for high-impact species were small and most (95.3\%) entered either as contaminants of seed or as pasture or turf (Table 2). High-impact species that are native to the Afrotropics or the Orient were more likely than random to be contaminants of seed (Table 2). This may be due to the influence of the genus Sporobolus. Of the six species from this genus that have naturalised in northern Australia, five arrived as contaminants and each of those is a high-impact species, three from the Afro-Tropical region and one from the Orient. Highimpact species were also more likely to be widely distributed Old World species imported as pasture (Table 2). (b) First records of high-impact species $(n=21)$

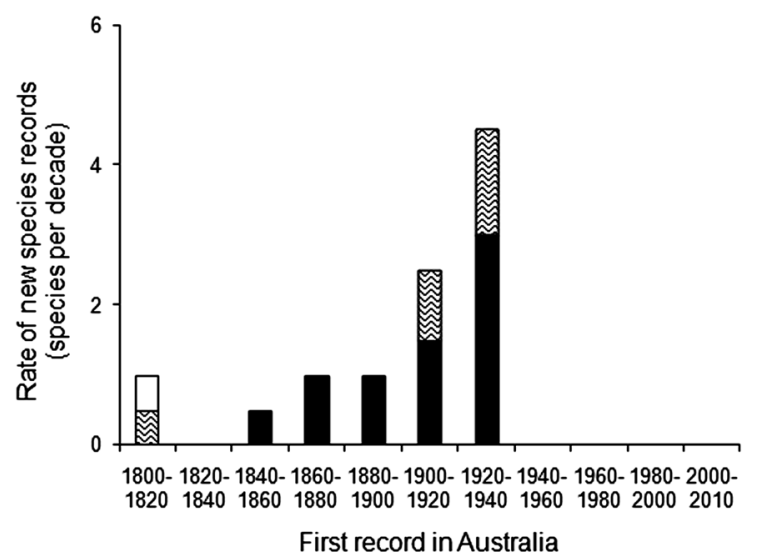

(d) Naturalisation of high-impact species ( $\mathrm{n}=21$ )

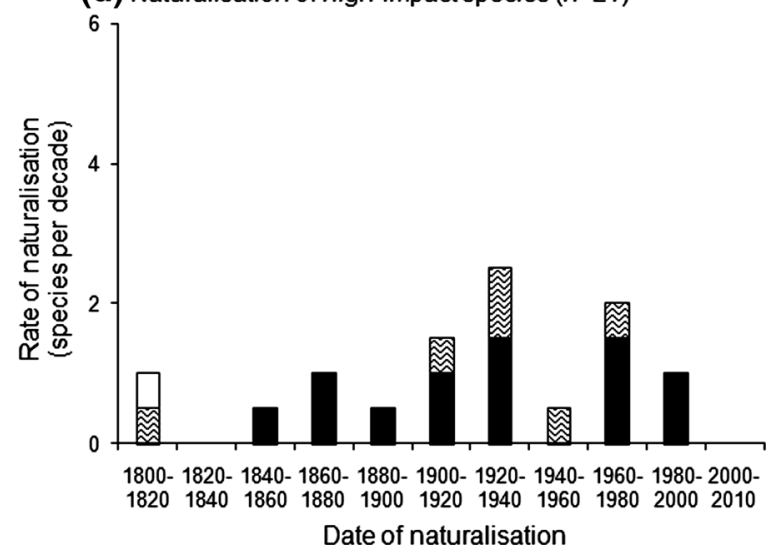

given for all species $(\mathbf{a}, \mathbf{c})$ and high-impact species $(\mathbf{b}, \mathbf{d})$. Note difference in $y$-axis scales between all species and high-impact species

History of importation

Most naturalised species (70.0\%) were first recorded in Australia between 1788 and 1940 (18.2 first records/ decade), peaking between 1921 and 1940 (Fig. 1a). Only four first records, or 1.3 per decade, have been reported in the 30 years from 1980, much lower than the long-term average of 7.4 per decade.

A similar pattern of first records was evident for high-impact species, peaking between 1921 and 1940 (38.1\% of species or 4.0 records per decade, against a long term average of 1.0 per decade) (Fig. 1b). All high-impact species had already been recorded in Australia by 1940 .

Intentional introduction for use as pasture or turf was the dominant introduction pathway prior to 1980 


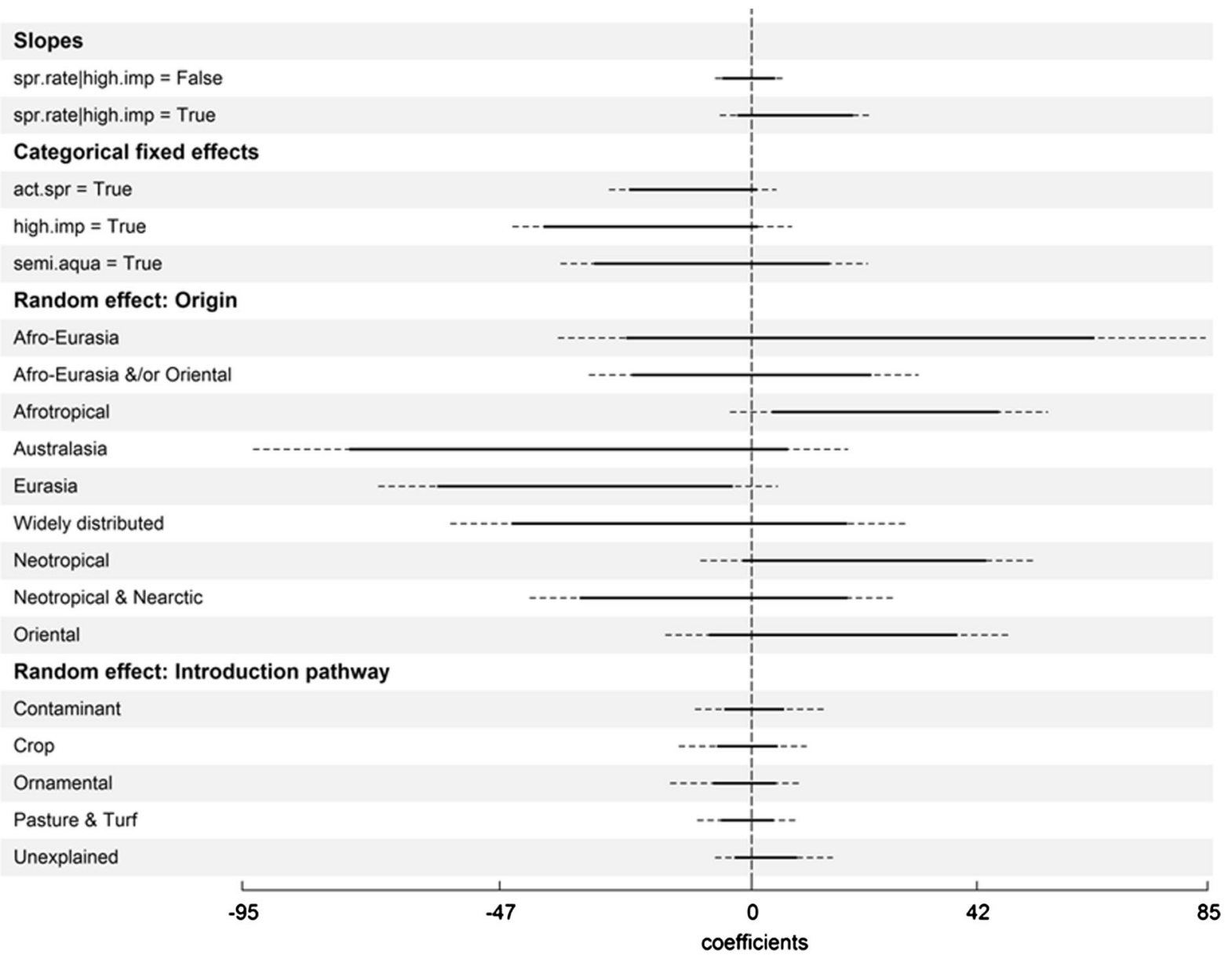

Fig. 2 Predictors of year of first record in Australia of tropical grasses showing credible intervals for the coefficients of each variable: $95 \%$ (solid line) and $99 \%$ (dashed line). Coefficients

(Fig. 1a), peaking with 34 first records between 1921 and 1940 (17 naturalisations/decade). Species that were probably introduced as crops $(7.7 \%)$, ornamentals $(4.5 \%)$ or contaminants of seed $(9.0 \%)$ became naturalised at low rates throughout (1.6 naturalisations per decade), as did unexplained introductions (1.05 naturalisations per decade) (Fig. 1a). Of the 13 species first recorded since 1960, only six are likely to have resulted from intentional introductions, including four as pasture or turf, one as an ornamental and one as a crop.

First records of species introduced as pasture or turf that are now high impact were already occurring by the mid 1800s, and peaked between 1920 and 1940 (five species). Five of the six high-impact species imported as contaminants were first recorded between 1900 and for all categorical fixed effects and random effects are differences from the intercept; $95 \%$ credible interval on the intercept was -25.1 to 14.7

1940 (Fig. 1b), which contrasted with all naturalised species (Fig. 1a).

Predictors of year of first record

On average, species that subsequently caused high impact were actively spread and were imported earlier than other species (upper limits of the $95 \%$ credible intervals are at or very near 0 in Fig. 2). Origin also had an effect on date of first record. Species from Eurasia tended to be introduced earlier than others, while those from the Afro-tropical region and the Neotropics tended to be introduced later (Fig. 2). Different introduction pathways have not changed in importance over time (introduction pathway had no effect, as shown in Fig. 2). 
History of naturalisation

About half of the species $(50.3 \%)$ were already naturalised when first recorded (Figure S1). This included $71.4 \%(\mathrm{n}=14$ species $)$ of species introduced as contaminants but only $25.0-33.3 \%$ of species introduced as ornamentals, crops and pasture or turf. Few species $(13.8 \%, \mathrm{n}=38)$ that naturalised prior to 1900 had been previously recorded in Australia, whereas most species $(75.0 \%, \mathrm{n}=64)$ that naturalised after 1932 had been previously recorded (Figure S1). A similar trend was apparent for high-impact species, where only one species (Cenchrus ciliaris) that naturalised by 1932 had been previously recorded in Australia, compared to all seven species that naturalised after 1932 (Figure S1).

Where gaps between introduction and naturalisation were recorded, they were considerable (mean $=27.4$, $\mathrm{SE} \pm 2.2$ years; maximum 124 years; $\mathrm{n}=77$ species), including gaps for high-impact species (30.2, $\mathrm{SE} \pm 2.4$ years; maximum 63 years; $\mathrm{n}=14$ species) (Figure S1). This resulted in relatively high rates of naturalisation continuing through to the 1970s (Fig. 1c), even though first records were low (Fig. 1a). Highimpact species continued to naturalise through to 1988 , despite the last first record being in 1940 (Fig. 1b).

Pasture grass history

Of the 100 species that were considered to have been imported as pasture (Fig. 2), 94 were on the Commonwealth Plant Introduction (CPI) list, including 55 species within a decade of inception of the list. Most CPI-listed pasture species were first recorded in Australia prior to commencement of the systematic survey efforts that followed WW2 (Fig. 3a). Also, most CPI-listed species were already naturalised at the time of listing (64 species), and a further nine species had previously been recorded in Australia (Figures S1, 3a). Sixteen of the remaining 21 species for which the CPI list represents the first record in Australia were listed prior to WW2 (Fig. 3a). As a result, naturalisation rates declined $(p<0.0001)$ from $10 \%$ when the CPI list commenced to $<5 \%$, despite ongoing introductions (Fig. 4).

The pattern is much the same for the 14 high-impact species imported as pasture, all of which have been recorded on the CPI list (Fig. 3b). Nine of those were already naturalised at the time of listing and a further four species had already been reported in Australia.
All CPI-listed pasture species that became highimpact were recorded by 1940, but five naturalised only during the systematic research phase after WW2. The last high-impact species to be first recorded on the CPI list was Cenchrus pedicellatus, recorded in 1940 and naturalised in 1961, and the last naturalisation (Hymenachne amplexicaulis) occurred in 1988.

Comparison to total Australian flora (1971-1995)

Of the 290 plant naturalisations in Australia between 1971 and 1995 (Groves 1998), most species (65\%) entered Australia as ornamentals (Table 3). Grass naturalisation ( $\mathrm{n}=18$ species) during the same period in our study demonstrated a similar proportion of species being introduced intentionally (72 vs $78 \%$ ), but these entered for use in agriculture $(67 \%)$ rather than as ornamentals (Table 3 ). The importance of unintentional or unexplained pathways was similar between all species and grasses separately, although entry as contaminants of seed was more important for grasses. The relative importance of different pathways was, however, very different for grasses when first records rather than naturalisations were considered for 1971-1995 (Table 3). Unintentional pathways were the most important, with only two species introduced for agriculture. Comparative importation data on all flora were not available.

\section{Discussion}

Our historical analysis of tropical grass naturalisations in Australia revealed patterns that are counter to a general expectation in invasion ecology, that of increasing naturalisations with time as global trade has increased (Elton 1958; Lowe 2004; Hulme 2009). We detected no changes since European settlement in rates of first records or naturalisations of species that entered Australia through unintentional pathways (contaminants of seed or unexplained); for these plants a proportional increase with globalisation might be expected. Furthermore, the last high-impact species to enter through unintentional pathways had naturalised by 1969 . However, intentional introduction was the predominant pathway (77\% of naturalised species), which is comparable to other invasive plant taxa in Australia (Groves 1998; Harris et al. 2007). Most $(85 \%)$ of the naturalised grass species had already 
Fig. 3 History of tropical grass species listed on the Commonwealth Plant Introduction (CPI) List (commenced 1929) that were imported for pasture (a), and the subset of those species that caused high impact (b). Cumulative records are given for time of first record on the CPI list and in Australia, time of naturalisation and for the subset of species where CPI listing was the first record in Australia. Pasture research phases are shown in (b) and the cumulative total number of C4 grass species recorded on the CPI list in (a). Most tropical grass species have a C4 photosynthetic pathway, which therefore serves as a good proxy for introduction effort
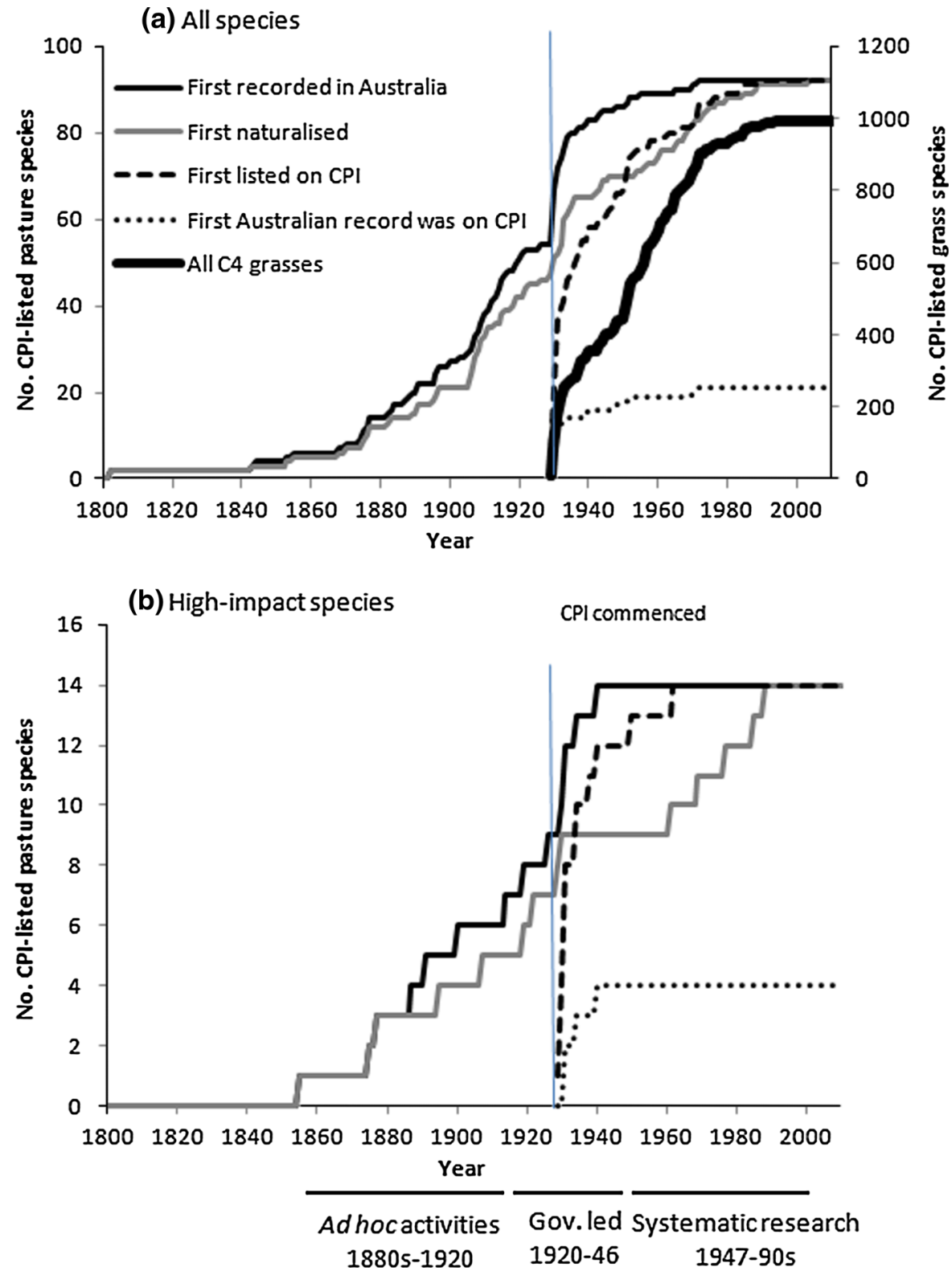

been reported in Australia prior to 1940, and all highimpact species had been reported by then. This was despite ongoing, systematic efforts to source and establish new pasture species, the primary pathway, through much of the twentieth century (Eyles and Cameron 1985; Winter et al. 1985; Cook and Dias 2006). The subsequent decline in naturalisation rates to historical lows therefore suggests the pool of new, potentially useful pasture grass species was being depleted. Nonetheless, the pasture research program was responsible for five of the seven high impact species naturalising since 1932, all first imported prior by 1940 . The border protection system was first tightened in the 1990s, with the institution of the Weed Risk Assessment system at the Australian border in 1997 (Pheloung 2001; Weber et al. 2009). This was too late for its effect on naturalisation rates to be tested.

Naturalisation rates are reportedly continuing to increase for many taxa and geographic regions (Groves 1998; Hulme 2009; Pyšek et al. 2009). However, information on patterns of importation rates for species that subsequently naturalise is required to 

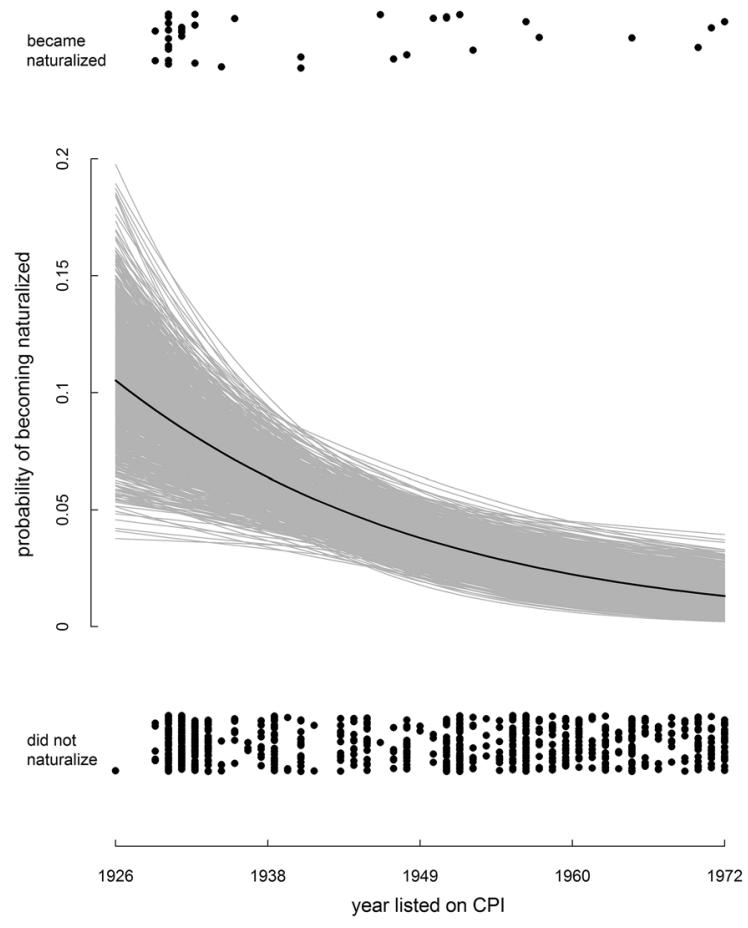

Fig. 4 Probability a tropical grass species becoming naturalized as a function of the year it was listed on the Commonwealth Plant Introduction List (CPI). Black line shows the prediction of the model fitted to the observed data. To show uncertainty around this prediction, grey lines are the predictions of 1000 models, each fit to a data set simulated from the original model (using the 'simulate' function in R). Only species listed on the CPI before 1972 (the last year a naturalized C4 grass was introduced) are used in the analysis, to reduce the effect of the lag time between introduction and naturalisation on the result. Species that had naturalized prior to CPI listing, or weren't listed on the CPI, were excluded. Black points show the observed data, with one point per species (jittered on the $y$-axis to help separate overlying points) provide insights into future trends in naturalisation rates, especially when there are long lag phases between introduction and naturalisation. In our study most species that naturalised since 1930 had a lag phase, which averaged 27 years. Although less than the 100 years observed in studies of woody-weed flora in South Australia (Caley et al. 2008) and Brandenburg Forest, Germany (Kowarik 1995), it still means that grass invasions are to a large extent the consequence of historical activities, or invasion debt (Essl et al. 2011). A focus on naturalisation rates to predict future trends can therefore be misleading, as a comparison between a census of naturalised flora in Australia between 1970 and 1995 (Groves 1998) and the present study demonstrate (Table 3 ). The proportion of intentionally introduced species that naturalised during that period was comparable (72\%). However, most grass species first recorded during that period that subsequently naturalised entered through unintentional pathways. This reflects the general decline in importance of intentional pathways in our grass analysis, and the expected return to low levels of naturalisations that result largely from unintentional introductions. Whether the observed recent increase in naturalisations in other studies (Groves 1998; Hulme 2009; Pyšek et al. 2009) is a consequence of a historical peak in introductions, or reflects a continued increase in rates of introductions that will ultimately naturalise, requires further testing. This includes obtaining a better historical understanding of the ornamental pathway.

The general expectation in biosecurity is that patterns of naturalisation will increase with trade

Table 3 Comparison of introduction pathways between the present study on tropical grasses naturalised in northern Australia and all plant naturalisation in Australia between 1971 and 1995 (Groves 1998)

\begin{tabular}{|c|c|c|c|c|}
\hline & \multicolumn{3}{|c|}{ Current study (tropical grasses) } & \multirow{2}{*}{$\frac{\text { Groves (all flora) }}{\text { Naturalised: } 1971-1995}$} \\
\hline & Total: $1788-2009$ & First record: 1971-1995 & Naturalised: 1971-1995 & \\
\hline \multicolumn{5}{|l|}{ Intentional pathway } \\
\hline Agriculture (includes pasture) & $72.9 \%$ & $28.6 \%(2)$ & $66.7 \%(12)$ & $7 \%(20)$ \\
\hline Ornamental & $4.5 \%$ & $14.2 \%(1)$ & $5.6 \%(1)$ & $65 \%(189)$ \\
\hline Other & & & & $6 \%(17)$ \\
\hline \multicolumn{5}{|c|}{ Unintentional or unexplained pathways } \\
\hline Contaminant & $9.0 \%$ & $0 \%(0)$ & $11.1 \%(2)$ & $2 \%(6)$ \\
\hline Unknown & $13.5 \%$ & $57.1 \%(4)$ & $16.7 \%(3)$ & $20 \%(58)$ \\
\hline Number of species & 155 & 7 & 18 & 290 \\
\hline
\end{tabular}


volume, and will be responsive to changes in trading patterns and pathways. We have noted historical reasons for the observed patterns in introductions that resulted in the naturalisation of tropical and subtropical grasses. Patterns were much the same for all naturalisations and the high-impact species, although the latter were more likely than random to be Old World species introduced for use in pastures. Early in Australia's settlement the predominant source was Europe and Eurasia, reflecting early Australian ties to Europe. The tropical regions of Africa and the Americas became important around the 1920s, possibly as government-sponsored pasture improvement programs started looking further afield for potential pasture species (Eyles and Cameron 1985; Winter et al. 1985; Cook and Dias 2006). This was despite strong interest in finding tropical forage species for northern Australia since at least the 1860s (Chudleigh and Bramwell 1996; Cook and Dias 2006). However, no increases in first records, or naturalisations, were observed with the sharp increases in trade and globalisation observed over the past several decades (Hulme 2009). Since the 1930s there was also little shift in the geographic origins of naturalised grass species in northern Australia, despite profound social and economic changes. For example, trading partners, including countries such as China, have changed dramatically in the past few decades (International Monetary Fund 2011). This was true for either unintentional pathways (where a closer link to trade might be expected) or intentional pathways. This may be because general trade is not an important pathway for new grass species into Australia. Other possibilities that require testing are that new trading partners have limited pools of species that are likely to invade through those pathways, or that the nature of new trade is such that introduction and establishment probabilities remain low despite increased trade.

Explaining patterns of introduction, and subsequent naturalisation, requires an historical understanding of the important pathways that resulted in introductions and subsequent naturalisations. In our study patterns of introduction were more a consequence of specific demand and interests, rather than general trends in globalisation and trade per se. That is, tropical and subtropical pasture grass introductions into Australia reflected dedicated activities by acclimatisation societies, and ad hoc introductions, through the late $1800 \mathrm{~s}$ and early 1900s, followed by a much more co- ordinated government-sponsored pasture research program through to the 1990s (Eyles and Cameron 1985; Winter et al. 1985; Cook and Dias 2006). Historical drivers of introductions may also be important for other flora that entered Australia (Groves 1998; Harris et al. 2007; Caley et al. 2008) and elsewhere (Myers and Bazely 2003; Hulme 2009; Richardson and Rejmánek 2011), which were predominantly introduced for use as ornamentals.

The common expectation of continually increasing rates of naturalisation (Westphal et al. 2008) rests on the assumption that there is an inexhaustible source of potential invaders, including those that can cause serious impact. In contrast, our evidence suggests that this may not be the case for grass species being considered for pasture in Australia. Most prospective pasture grass species had already been considered, at least to the point of having been imported into Australia, by relatively ad hoc activities prior to 1920 (47 species), and by the emerging governmentlevel research program in northern Australia from the 1920s through to WW2 (36 species). This included all 14 high-impact species imported as pasture. The first of these was Megathyrsus maximus, which was reportedly introduced as a forage species in 1867 by the Queensland Acclimatisation Society (Eyles and Cameron 1985), although it had already been recorded on the Brisbane River in 1855. The low naturalisation rate of new pasture species after WW2 is also reflected in the overall decline in naturalisation rates as a proportion of total new CPI-listed introductions, from 10 to $<5 \%$, between 1929 and 1972, and pre-dates any expected effects of tightening border protection. Concerns regarding negative environmental impacts of grasses were first raised in the 1980s (Hazard 1988; Lonsdale 1994; Cook and Dias 2006) and only formally addressed in the 1990s (Weber et al. 2009). Low establishment rates after WW2 also do not reflect a decline in effort directed at finding and establishing new pasture species. If anything, effort increased. The stated vision to replace "native vegetation by improved pasture across all of the wetter third of Australia" (Davies 1953; Cook and Dias 2006) reflected the sense of purpose and optimism of the times. The area under sown pasture increased significantly in northern Australia from the 1950s (Chudleigh and Bramwell 1996) and research effort also became better directed. For example, systematic collecting missions commenced in 1947 aimed at 
finding species that could form self-sustaining populations in Australian conditions (Lonsdale 1994). This resulted in 16 significant plant-collecting expeditions through to 1981 (Eyles and Cameron 1985) and high levels of species discovery as reported on the CPI list (Fig. 3a: $60.3 \%$ of 2,250; Cook and Dias (2006)), but yielded at most five species that subsequently naturalised. Efforts to establish new species also become increasingly systematic through the establishment of field research stations across northern Australia (Lonsdale 1994). We therefore conclude that the reduction in naturalisation rates of intentionally introduced species was the result of a declining pool of species that appeared useful. A similar conclusion was drawn regarding weeds of New Zealand agricultural systems by Williams et al. (2010, p. 98), who stated "Declining naturalization rates in recent decades, especially of agricultural weeds, may also be attributed to the fact that the majority of temperate weeds suitable of New Zealand climates had already been imported by the middle of last century."

The outcome of the dedicated pasture grass research program since WW2 was not species discovery, but ensuring that the most promising of the previously imported species became naturalised and reached their full potential, reflecting the lag phases typical for the development of agricultural technologies (Alston et al. 2009). This was evidenced by continued naturalisations of as many as 28 species through to the 1980s. All had already been imported previously into Australia, including five of the seven high-impact species that naturalised since WW2, for four of which the CPI records represent their first record in Australia (1929-1940). Preferential selection of perennial, high biomass species that would become self-sustaining (Lonsdale 1994) probably contributed to the bias towards species that subsequently caused serious environmental impacts (all five high-impact environment species that naturalised since 1947). Activity also focussed on the continued introduction of new cultivars of already-naturalised pasture species (Eyles and Cameron 1985; Cook and Dias 2006; Friedel et al. 2011). The role of introducing additional genetic diversity has not been quantified, but is expected to have increased the environmental niche of some species (Grice et al. 2012). New records and naturalisations of pasture species dropped to low levels by the late 1970 s, coinciding with reduced funding for agricultural research and a switch of research focus to cropping (Eyles and Cameron 1985). The low rate of successful pasture introductions in the latter half of the 1900s may also have played a role.

\section{Conclusions}

Increased globalisation, and the associated international connectivity, has not translated into increased invasion risks for tropical and subtropical grasses in Australia, both when considering overall rates of naturalisation and naturalisation of high-impact species. This includes unintentional introductions, for which a correlation with trade might be expected. As such, it challenges the prevailing view that increased globalisation will inevitably lead to increased rates of homogenisation of our flora and fauna. More generally it suggests a more evidence-based approach is required to test fundamental hypotheses in biosecurity, taking into account both intentional and unintentional pathways and the often substantial time lags between first introduction, naturalisation and impact. This includes determining whether any observed increases in naturalisation are the consequence of historical, ongoing or emerging introduction trends, and whether any increases are really the result of changes in the volume or nature of trade. Our results suggest that in the absence of changes in introduction pathways, continued increases in naturalisation rates should not be assumed, as species pools can become depleted for specific pathways.

The introduction history of high-impact species was much the same as for naturalisations overall, so in this case the biosecurity implications are likely to be similar whether the goal is minimising all naturalisations or just naturalisation of high-impact species, albeit with a seven-fold lower base rate for naturalisations of species that result in serious impacts (1.2 species/decade over the past 50 years). Opportunities to further reduce naturalisation rates of grasses resulting from unintentional entry through additional tightening of border protection protocols may be limited in the absence of new introduction pathways. Seed screening for contaminants has been underway at least since the 1950s for seeds used in research (Cook and Dias 2006), naturalisation rates following entry as seed contaminants remains at historically low levels, and the last high-impact species thought to have entered in this way 
(Sporobulus natalensis) was naturalised by 1969. In contrast, Weed Risk Assessments (first put in place in 1997) may arguably have prevented the naturalisation of several high-impact species intentionally released since WW2, had such assessments been required earlier. They may also prevent the release of new high-impact species, including those related to emerging pathways, such as importation of grasses to manage salinity (Stone et al. 2008) and as biofuel (Raghu et al. 2006). WRA relies on identifying the species that have the potential to cause serious impact, but finding reliable predictors for impact has proven difficult and therefore requires much more work (van Klinken et al. 2013). Greater emphasis on cost-benefit analysis, which is currently missing from WRA, may also be required (Yokomizo et al. 2012). The five pasture species naturalised since 1960 that resulted in serious negative impacts, may not have been permitted entry if a cost-benefit analysis had been undertaken: two (Cenchrus pedicellatus and $C$. polystachios) have limited palatability (Hazard 1988), one (Andropogon gayanus) requires relatively intensive management to remain palatable (Cook et al. 2005), and two semi-aquatic species (Echinochloa polystachya and Hymenachne amplexicaulis) were introduced for a niche application aimed at developing ponded (periodically flooded) pasture (Wildin 1991; Wearne et al. 2010). WRA should also be extended to considering the risk of introducing additional cultivars of existing species, as these can extend potential impacts (Grice et al. 2012). Our expectation is that with continued border security, and in the absence of new pathways, grass naturalisation rates will remain low, and potentially continue to fall. We may therefore have seen the worst of new grass introductions in Australia. This suggests that, for this group of species, biosecurity efforts need to be increasingly focussed on anticipating and minimising the negative potential impacts of plants that are already in Australia.

Acknowledgments We thank Colin Wilson, Barbara Ross, Anna Marcora and Celine Clech-Goods for assistance in compiling and analysing the data, Anne Bourne and S. Raghu for statistical assistance, S. Raghu, Dean Paini and Garry Cook for comments on an earlier draft and access to unpublished data, and members of the Global Invasion Network for valuable discussions. The Caring for Our Country program provided funding assistance through project X0000001326G.
Open Access This article is distributed under the terms of the Creative Commons Attribution License which permits any use, distribution, and reproduction in any medium, provided the original author(s) and the source are credited.

\section{References}

Aikio S, Duncan RP, Hulme PE (2010) Lag-phases in alien plant invasions: separating the facts from the artefacts. Oikos 119:370-378

Alston JM, Beddow JM, Pardey PG (2009) Agricultural research, productivity, and food prices in the long run. Science 325:1209-1210

Bates D, Bolker B (2012) CRAN-Package lme4. In. http://cran. r-project.org/web/packages/lme4/index.html

Caley P, Groves RH, Barker R (2008) Estimating the invasion success of introduced plants. Divers Distrib 14:196-203

Chudleigh PD, Bramwell T (1996) Assessing the impact of introduced tropical pasture plants in Northern Australia. Agtrans Research, Toowong

Cook GD, Dias L (2006) It was no accident: deliberate plant introductions by Australian government agencies during the 20th century. Aust J Bot 54:601-625

Cook B, Pengelly BC, Brown SD, Donnelly JL, Eagles DA, Franco MA, Hanson J, Mullen BF, Partridge IJ, Peters M, Schultze-Kraft R (2005) Tropical forages: an interactive selection tool (CD-ROM). CSIRO, DPIF (Qld), CIAT and ILRI, Brisbane

Core Team R (2012) R: a language and environment for statistical computing. R Foundation for Statistical Computing, Vienna

Daehler CC (2009) Short lag times for invasive tropical plants: evidence from experimental plantings in Hawai' i. Plos One 4:e4462

D’Antonio CM, Vitousek PM (1992) Biological invasions by exotic grasses, the grass/fire cycle, and global change. Annu Rev Ecol Syst 23:63-87

Davies JG (1953) Research reveals a new Australia. Rural Res 3:2-7

Elton C (1958) The ecology of invasions by animals and plants. Methuen, London

Essl F, Dullinger S, Rabitsch W et al (2011) Socioeconomic legacy yields an invasion debt. Proc Natl Acad Sci 108:203-207

Ewel JJ, O’Dowd DJ, Bergelson J et al (1999) Deliberate introductions of species: research needs. Bioscience 49:619-630

Eyles AG, Cameron DG (1985) Pasture research in northern Australia-its history, achievements and future emphasis. CSIRO Australia, Division of Tropical Crops and Pastures, Brisbane

Ferdinands K, Beggs K, Whitehead P (2005) Biodiversity and invasive grass species: multiple-use or monoculture? Wildl Res 32:447-457

Friedel MH, Grice AC, Marshall NA, van Klinken RD (2011) Reducing contention amongst organisations dealing with commercially valuable but invasive plants: the case of buffel grass. Environ Sci Policy 14:1205-1218 
Grice A, Friedel M, Marshall N, van Klinken RD (2012) Tackling contentious invasive plant species: a case study of buffel grass in Australia. J Environ Manag 49:52-62

Groves RH (1998) Recent incursions of weeds to Australia 1971-1995. CRC for Weed Management Systems Technical Series 3, 1-74

Groves RH, Boden R, Lonsdale M (2005) Jumping the garden fence: invasive garden plants in Australia and their environmental and agricultural impacts. WWF-Australia, Ultimo

Harris CJ, Murray BR, Hose GC, Hamilton MA (2007) Introduction history and invasion success in exotic vines introduced to Australia. Divers Distrib 13:467-475

Hazard WHL (1988) Introducing crop, pasture and ornamental species into Australia - the risk of introducing new weeds. Aust Plant Introd Rev 19:19-36

Holtze M (1890) Report on the progress and condition of the Government Botanic Garden and Experimental Nursery. Government Residents Report for the Northern Territory for the year, South Australia, pp 8-10

Hulme PE (2009) Trade, transport and trouble: managing invasive species pathways in an era of globalization. J Appl Ecol 46:10-18

International Monetary Fund (2011) Changing patterns of global trade. In: Strategy, policy, and review department. http:// www.imf.org/external/np/pp/eng/2011/061511.pdf. Accessed 24 July 2013

Kowarik I (1995) Time lags in biological invasions with regard to the success and failure of alien species. In: Pyšek P, Prach K, Rejmánek M, Wade M (eds) Plant invasions: general aspects and special problems workshop held at Kostelec nad Černými lesy, Czech Republic, 16-19 September 1993, pp 15-38

Lonsdale WM (1994) Inviting trouble-introduced pasture species in northern Australia. Aust J Ecol 19:345-354

Lowe SJ (2004) 100 of the world's worst invasive alien species: a selection from the global invasive species database/[S. Lowe... et al.]. Invasive Species Specialist Group

Mack RN (1989) Temperate grasses vulnerable to plant invasions: characteristics and consequences. In: Drake JA, Mooney HA, di Castri F (eds) Biological invasions: a global perspective. Wiley, Chichester, pp 155-179

Mack RN, Erneberg M (2002) The United States naturalized flora: largely the product of deliberate introductions. Ann Mo Bot Gard 89:176-189

Meyerson LA, Mooney HA (2007) Invasive alien species in an era of globalization. Front Ecol Environ 5:199-208

Mott JJ (1986) Planned invasions of Australian tropical savannas. In: Groves RH, Burdon JJ (eds) Ecology of biological invasions. University Press, Cambridge, pp 89-96

Myers JH, Bazely D (2003) Ecology and control of introduced plants. Cambridge University Press, New York

Oksanen J, Blanchet FG, Kindt R et al (2013) vegan: Community Ecology Package. In. http://cran.r-project.org/web/ packages/vegan/index.html. Accessed 21 Nov 2013

Perrings C, Mooney HA, Williamson MMH (2010) Bioinvasions and globalization. Oxford University Press, Oxford

Pheloung P (2001) Weed risk assessment for plant introductions to Australia. In: Groves RH, Panetta FD, Virtue JG (eds) Weed risk assessment. CSIRO Publishing, Collingwood, pp 83-92
Plummer M, Best N, Cowles K, Vines K (2006) CODA: convergence diagnosis and output analysis for MCMC. R News 6:7-11

Pysek P, Jarosik V, Hulme PE, Pergl J, Hejda M, Schaffner U, Montserrat V (2012) A global assessment of invasive plant impacts on resident species, communities and ecosystems: the interaction of impact measures, invading species' traits and environment. Glob Chang Biol 18:1725-1737

Pyšek P, Lambdon PW, Arianoutsou M, Kuhn I, Pino J, Winter M (2009) Alien vascular plants of Europe. In: Drake JA (ed) Handbook of alien species in Europe-Springer Series in Invasion Ecology, vol 3, pp 43-61

Raghu S, Anderson RC, Daehler CC et al (2006) Adding biofuels to the invasive species fire? Science 313:1742

Richardson DM, Rejmánek M (2011) Trees and shrubs as invasive alien species-a global review. Divers Distrib 17:788-809

Richardson DM, Pyšek P, Rejmánek M, Barbour MG, Panetta FD, West CJ (2000) Naturalization and invasion of alien plants: concepts and definitions. Divers Distrib 6:93-107

Rosenzweig ML (2001) The four questions: what does the introduction of exotic species do to diversity? Evol Ecol Res 3:361-367

Setterfield SA, Rossiter-Rachor NA, Hutley LB, Douglas MM, Williams RJ (2010) Turning up the heat: the impacts of Andropogon gayanus (gamba grass) invasion on fire behaviour in northern Australian savannas. Divers Distrib 16:854-861

Stone LM, Byrne M, Virtue JG (2008) An environmental weed risk assessment model for Australian forage improvement programs. Aust J Exp Agric 48:568-574

Su YS, Yajima M (2012) R2jags: a package for running jags from R. R package version 0.03-08

van Klinken RD, Panetta FD, Coutts SR (2013) Are high-impact species predictable? An analysis of naturalised grasses in northern Australia. PLoS One 8:e68678

Wearne LJ, Clarkson J, Grice AC, van Klinken RD, Vitelli JS (2010) The biology of Australian weeds. 56. Hymenachne amplexicaulis (Rudge) Nees. Plant Prot Q 25:146-161

Weber J, Panetta FD, Virtue J, Pheloung P (2009) An analysis of assessment outcomes from eight years' operation of the Australian border weed risk assessment system. J Environ Manag 90:798-807

Westphal MI, Browne M, MacKinnon K, Noble I (2008) The link between international trade and the global distribution of invasive alien species. Biol Invasions 10:391-398

Wildin J (1991) Aleman grass, hymenachne and other forage species for ponded pasture systems. In: Probing ponded pastures: proceedings of a workshop, July 1991. Queensland Department of Primary Industry and Fisheries, Brisbane, Queensland

Williams PA, Popay I, Gatehouse HAW (2010) New Zealand biosecurity legislation and the naturalization of exotic weeds. Plant Prot Q 25:95-98

Winter W, Cameron A, Reid R, Stockwell TG, Page MC (1985) Improved pasture plants. In: Muchow RC (ed) Agroresearch for the Semiarid Tropics: North-West Australia. University of Queensland Press, Brisbane, pp 227-269

Yokomizo K, Possingham HP, Hulme PE, Grice AC, Buckley YM (2012) Cost-benefit analysis for intentional plant introductions under uncertainty. Biol Invasions 14: 839-849 